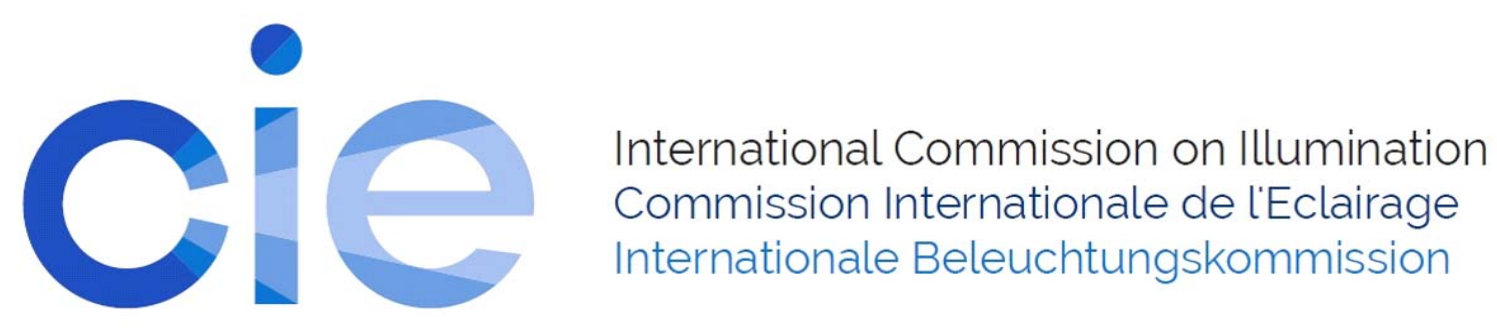

P0186

\title{
VISIBILITY IMPROVEMENT BY CCT TUNABLE LED HEADLAMP UNDER THE ADVERSE WEATHER CONDITIONS
}

\author{
Hyensou Pak et al.
}

DOI 10.25039/x46.2019.PO186

from

CIE x046:2019

Proceedings

of the

29th CIE SESSION

Washington D.C., USA, June 14 - 22, 2019

(DOI 10.25039/x46.2019)

The paper has been presented at the 29th CIE Session, Washington D.C., USA, June 14-22, 2019. It has not been peer-reviewed by CIE.

\section{(C) CIE 2019}

All rights reserved. Unless otherwise specified, no part of this publication may be reproduced or utilized in any form or by any means, electronic or mechanical, including photocopying and microfilm, without permission in writing from CIE Central Bureau at the address below. Any mention of organizations or products does not imply endorsement by the CIE.

This paper is made available open access for individual use. However, in all other cases all rights are reserved unless explicit permission is sought from and given by the CIE.

CIE Central Bureau

Babenbergerstrasse 9

A-1010 Vienna

Austria

Tel.: +4317143187

e-mail: ciecb@cie.co.at

www.cie.co.at 


\title{
VISIBILITY IMPROVEMENT BY CCT TUNABLE LED HEADLAMP UNDER THE ADVERSE WEATHER CONDITIONS
}

\author{
Pak, H. ${ }^{1}$, Lee, C-S. ${ }^{1,2}$ \\ 1 ALLICE, Yeungnam University, Gyeongsan, SOUTH KOREA, \\ 2 Dept. of Electronic Engineering, Yeungnam University, Gyeongsan, SOUTH KOREA
}

hspak@ynu.ac.kr

DOI 10.25039/x46.2019.PO186

\begin{abstract}
Since visibility is a very important factor under the adverse weather conditions like fog, rain, snow, and yellow dust and much more in nighttime, we need to understand the characteristics of visibility under the conditions. For this reason, we built two test-beds to simulate the adverse weather conditions, one for fog, rain, and snow and the other for yellow dust. We also developed a set of CCT tunable LED automotive headlamp for the evaluation of the visibility in different CCT headlamp. The CCT of the headlamp used for the experiments was $3000 \mathrm{~K}$ and $6500 \mathrm{~K}$, and we measured the reflective luminance on the visual targets and calculated the relative luminance and contrast ratio. Additionally, we collected the subjective evaluation data. The results showed that the visibility was higher at low CCT in fog and rain but it was higher at high CCT in snow and yellow dust. Likewise, subjective evaluation showed the similar tendency.
\end{abstract}

Keywords: Visibility, Adverse Weather Condition, CCT Tunable, LED Headlamp

\section{Introduction}

Visibility is one of the most important factors for the visual performance and traffic safety on the road environment (Adrian, 1989). Particularly, it is critical when people drive under the adverse weather conditions like fog, rain, snow, and yellow dust and much more in nighttime (Zaini et al., 2009). Driving at such situations seriously threats the safety of pedestrians as well as drivers (Gallen et al., 2015). However, there is not enough research on the characteristics of visibility under the adverse weather conditions in nighttime until now because there is some difficulties to control the weather conditions and to perform the experiment. Therefore, in the first place, it is necessary to understand the visibility using artificial adverse weather conditions and systematic experiments, and then to find out some implications from the results. The result can be used to develop headlamp to improve visibility under the adverse weather conditions.

\section{Methods}

\subsection{Experimental Setup}

For this research, we built two test-beds to simulate the adverse weather conditions, one for fog, rain, and snow $(3 \mathrm{~m} \times 3 \mathrm{~m} \times 12 \mathrm{~m})$ and the other for yellow dust $(1.2 \mathrm{~m} \times 1.2 \mathrm{~m} \times 8 \mathrm{~m})$. At the same time, we developed a set of CCT tunable LED headlamp for the diverse tests collaborating with some research institutes and companies. To control the artificial weather conditions, we changed the volume of incoming water or oil to the pipes and nozzles for the fog, rain and snow conditions, or manipulated the speed of fans for the yellow dust environment. Several types of visual targets including white and grey coloured non-reflective human shaped panels $(100 \mathrm{~cm}$ height), highly reflective 6 colour (red, white, green, blue, brown, and yellow) sheets $(20 \mathrm{~cm} \mathrm{x}$ $30 \mathrm{~cm}$ ), and a speed limit traffic sign. The CCT range of the headlamp was from $3000 \mathrm{~K}$ to $6500 \mathrm{~K}$, but we used the two CCT conditions, low CCT and high CCT for the measurement and observation. To check and meet the density of the fog, rain, snow, and yellow dust for the experimental conditions, we repeatedly measured the transmittance of the light emitting from a LED reference lighting using a Spectroradiometer (Konica-Minolta CS-2000). 

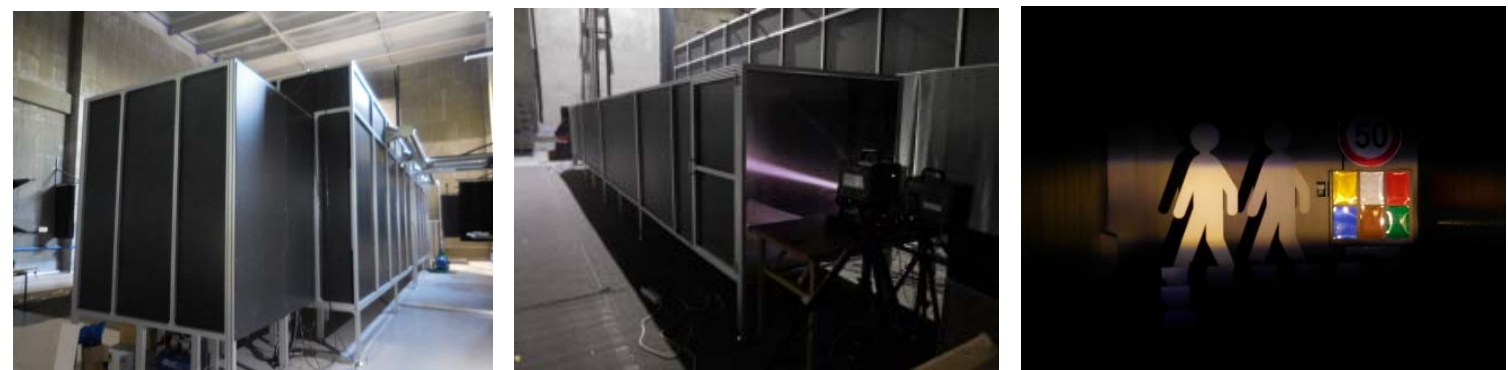

Figure 1 - Experimental Testbeds and Visual Targets

\subsection{Measurement}

Using the experimental setup, we measured the reflective luminance $\left(\mathrm{cd} / \mathrm{m}^{2}\right)$ from the visual targets of white and grey pedestrian shaped using 2-D colour analyser (Konica-Minolta CA2000). The number of measurements for each weather condition was 3 to 5 times and the luminance data was obtained from the specific spots on the targets. Then, we calculated the contrast ratio based on the average luminance values from each target. The contrast ratio was obtained by dividing the target luminance by target luminance minus background luminance. In addition, we collected the subjective evaluation (visibility rating) data from the university students who observed the visual targets in the same experimental conditions.

\section{Results}

\subsection{Luminance}

Luminance data from the visual targets showed that the visibility based on the luminance was higher at the low CCT in fog and rain conditions but at the high CCT in heavy snow and light yellow dust conditions.
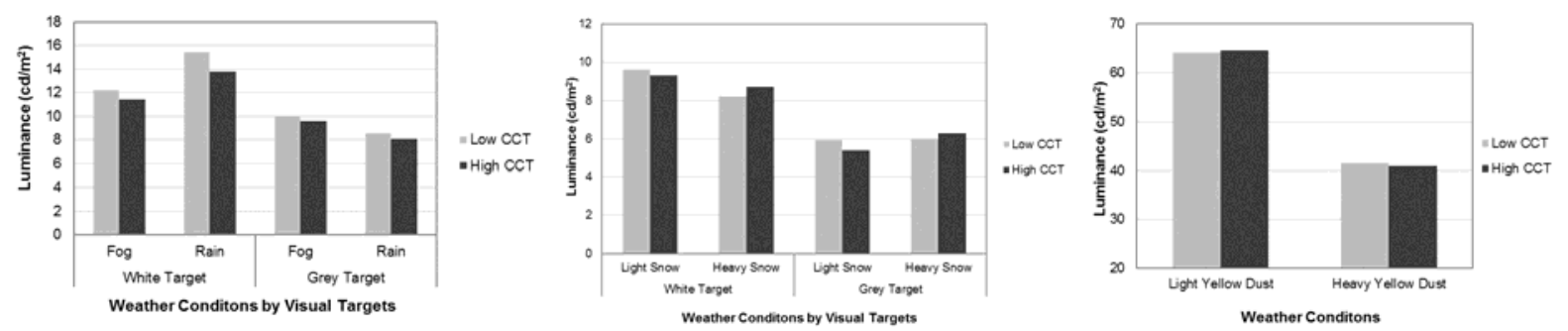

Figure 2 - Luminance Results under Fog, Rain, Snow, and Yellow Dust

\subsection{Contrast Ratio}

Contrast ratio calculated from the luminance between target and background showed that the visibility based on the contrast was higher at the low CCT in fog and rain conditions too, but at the high CCT in yellow dust conditions. Unfortunately, we do not have contrast data from the snow conditions because the luminance data from the background was under the dynamic range of the measurement.
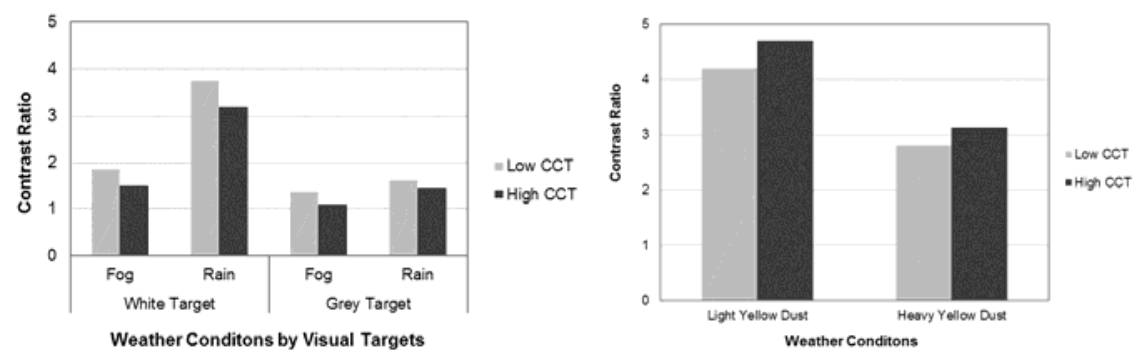

Figure 3 - Contrast Ratio Results under Fog, Rain, and Yellow Dust 


\subsection{Subjective Evaluation}

Subjective evaluation results from the visibility rating using 7-point scale under fog, rain, and yellow dust showed that the low CCT was better at the white and grey targets under fog and rain conditions, but the high CCT was better at the both targets under the yellow dust condition in the opposite way.

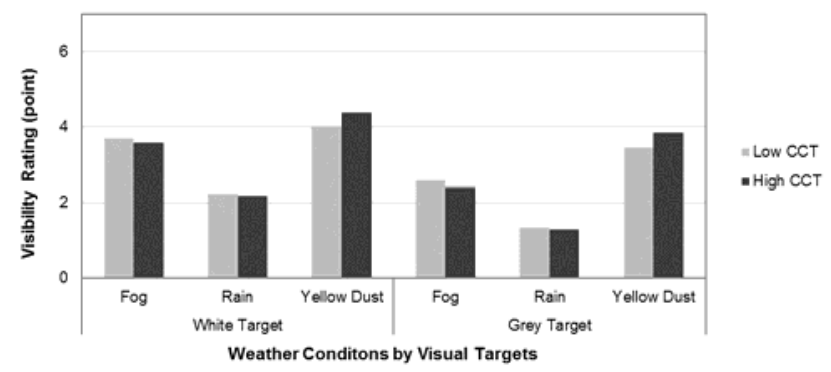

Figure 4 - Subjective Evaluation Results under Fog, Rain, and Yellow Dust

\section{Discussion and Conclusion}

According to the overall measurement and subjective evaluation data, the visibility was better at low CCT conditions under fog and rain conditions, but it was better at high CCT conditions under yellow dust condition. On the other hand, snow condition showed different luminance data according to the density, that is, low CCT was better under light snow but high CCT was better under heavy snow. However, the luminance and contrast ratio differences between high and low CCT conditions were very small and they showed a lot of variability. In addition, we did not obtain enough data from the snow condition that has actually quite different characteristics from the natural snow because it was generated from the oil-based snow machine.

Despite incomplete and unstable data, our results provided some implications on the visibility under adverse weather conditions and for the development of automotive headlamp that is adaptively functioning under the situations. For better understanding of the visibility under the adverse weather conditions, we need to consider the difference between the artificial weather conditions and the real ones, reliability of the measurement, validity of the visibility index, proper number of samples in the measurement and observation and so on.

\section{References}

ADRIAN, W. 1989. Visibility of Targets: Model for Calculation. Lighting Res. Technol., 21, 181188.

GALLEN, R., CORD, A., HAUTIERE, N., DUMONT, E., \& AUBERT, D. 2015. Nighttime Visibility Analysis and Estimation Method in the Presence of Dense Fog. IEEE Trans. Intell. Transp. Syst., 16(1), 310-320.

ZAINI, M., KUMIAWAN, B., NAKASHIMA, M., \& TAKAMATSU, M. 2009. Perceived brightness and saturation of Color LED light in dense fog at night time. J. Light \& Vis. Env., 33(2), 107-109.

\section{Acknowledgement}

This work was supported by the Technology Innovation Program (No. 10053045) and the Human Resources Program in the Transportation Specialized Lighting Core Technology Development (No. N0001364) granted financial resource from the Ministry of Trade, Industry \& Energy, Republic of Korea. 